\title{
Development of a Clinical Guide to Enhance Care for Suicidal Patients
}

\author{
Mark S. Oordt \\ Air Force Medical Support Agency \\ M. David Rudd \\ Baylor University
}

\author{
David A. Jobes \\ The Catholic University of America \\ Vincent P. Fonseca, Christine N. Runyan, \\ John B. Stea, Rick L. Campise, and \\ G. Wayne Talcott \\ Air Force Medical Support Agency
}

\begin{abstract}
Suicidal thoughts and behavior are common among mental health patients and are a source of stress for clinicians, who typically receive limited formal training on suicide. The U.S. Air Force initiated a project to enhance care and increase practitioner confidence when working with suicidal patients. A clinical guide was developed containing 18 recommendations for assessing and managing suicidality, strategies for meeting the recommendations, and clinical tools to facilitate quality care. Training opportunities and marketing efforts accompanied distribution of the guide. This initial article reviews the guide's development, content, and evaluation plan as a model that other health care systems, clinics, or training programs can follow to enhance care for suicidal patients. Outcome data will be presented in a follow-up article.
\end{abstract}

Keywords: U.S. Air Force, clinical guidelines, suicide

Suicidal symptoms, risk factors, and self-injurious behaviors are common among patients in mental health and substance abuse settings. For example, $31 \%$ of patients in outpatient mental health care reported suicidal ideation in one multisite study (Drozd, Lancaster, Zak, \& Peters, 2001). While completed suicide is uncommon, many mental health professionals experience a patient suicide sometime during their career. In fact, surveys suggest that one in two psychiatrists and one in five psychologists will experience at least one patient suicide (Chemtob, Bauer, Kinney, \& Hamada, 1988; Chemtob, Bauer, Torigoe, \& Hamada, 1988). Despite its prevalence, training on suicide assessment and intervention is both highly variable and often inadequate (Bongar \&
MARK S. OORDT received his $\mathrm{PhD}$ in clinical psychology from Fuller Theological Seminary Graduate School of Psychology and is board certified in health psychology. He has been senior behavioral health consultant to the U.S. Air Force Medical Service's Population Health Support Division and is now assigned to Aviano Air Base, Italy. His primary research area is in clinical health psychology.

DAvid A. Jobes received his $\mathrm{PhD}$ in clinical psychology from American University. He is a professor of psychology at The Catholic University of America and is a consultant to the U.S. Air Force Suicide Prevention Program. He is board certified in clinical psychology. His primary research focus is on clinical assessment, management, and treatment of suicidal patients.

M. DAVID RUDD received his PhD in clinical psychology from the University of Texas-Austin. He is board certified in clinical psychology. He is professor and chair of the Psychology Department at Baylor University. His primary research interest is in treatment of suicidal patients and suicide prevention, clinical suicidology, cognitive therapy, training to competence in high-risk areas, and regulatory issues in professional psychology.

VinCENT P. FONSECA received his MD from Boston University and his master's degree in quantitative methods from Harvard University. He is currently a physician epidemiologist consultant for the U.S. Air Force Medical Service's Population Health Support Division in San Antonio, Texas. He is board certified in general preventive medicine and public health. His areas of research and expertise are clinical quality improvement, clinical informatics, epidemiology and preventive medicine.

Christine N. RunYan received her PhD in clinical psychology from Virginia Tech University. She is currently employed by Intellica Corpo- ration. Her primary research interests include recognition of and early intervention in behavioral and psychiatric disorders in primary care clinics, behavioral disease prevention, population health, and health risk appraisal John B. STEA received his MD from the State University of New York. He is a preventive medicine consultant for the U.S. Air Force Medical Service's Population Health Support Division in San Antonio, Texas. He is a diplomate of the American Board of Psychiatry and Neurology. His primary research interests are in the areas of injury prevention and suicide prevention.

RICK L. CAMPISE received his PhD in counseling psychology from the University of Kansas. He is board certified in counseling psychology. He has served as the chief for the U.S. Air Force Suicide Prevention Program since 2001. His current research interests are suicide prevention, combat stress, deployment issues, and pediatric psychology.

G. WAYNE TALCOTT received his PhD in counseling psychology from the University of Missouri, Columbia. He is board certified in health psychology. He is currently chief of the U.S. Air Force Medical Service's Community Prevention Branch in San Antonio, Texas. Research interests include community-based prevention, chronic disease/illness, chronic pain rehabilitation, and health promotion/illness prevention.

THE VIEWS EXPRESSED IN THIS ARTICLE are those of the authors and do not reflect the official policy of the U.S. Department of Defense or the U.S. government. The Air Force Guide for Managing Suicidal Behavior can be downloaded at www.suicidology.org.

CORRESPONDENCE CONCERNING THIS ARTICLE should be addressed to Mark S. Oordt, PSC 54, Box 666, APO AE 09601. E-mail: mark@bluegood.com 
Harmatz, 1991; Ellis \& Dickey, 1998). Professional associations for mental health providers have only recently begun providing practice guidelines to their members on assessment and management of suicidal behaviors (American Psychiatric Association, 2003). It is therefore not surprising that patient suicide and suicidal behaviors are among the most stressful and anxiety-provoking aspects of clinicians' work (Pope \& Tabachnick, 1993). Clearly, mental health providers need guidance on incorporating clinical research findings and best practices into their work with suicidal patients.

Anxiety related to working with suicidal patients may partially stem from a societal trend toward holding mental health providers ethically responsible and sometimes legally liable in the event of a suicide (Jobes \& Berman, 1993). Throughout history, societal views have varied with regard to who should be held responsible for suicidal acts. Prior to the late 19th century, surviving family members were held liable and were legally persecuted and punished (Cantor, 2000), often resulting in loss of societal status and material wealth. Until approximately 50 years ago, suicide was considered a crime in most Western countries, and the individual who committed the act was deemed responsible. In modern times, however, mental health professionals may be held liable for a patient's self-harm. While the number of cases that actually go to trial is estimated to be relatively low (Gutheil, 1992), litigation can be pursued if there is a perception that the provider failed to appropriately assess risk or take precautions when risk was identified (Meyer, Landis, \& Hayes, 1988).

Further complicating the management of suicidal patients is the increasingly restrictive criteria for inpatient care. Although economic considerations have been the primary driving force behind the increasing demand on providers to provide outpatient treatment even for patients at relatively high risk for suicide (Jobes, 2000), clinical evidence has recently demonstrated that outpatient management of suicidal patients can be appropriate, safe, and often preferable to inpatient care. Rudd, Joiner, Jobes, and King (1999) critically reviewed the 20 controlled or randomized psychotherapy intervention and treatment studies related to suicide in the empirical literature at the time of their work. Despite methodological limitations, they drew the following conclusions:

1. Short-term improvements in treatment compliance for suicidal patients can be obtained through intensive follow-up, case management, telephone contacts, or home visits.

2. Improved ease of access to emergency services can reduce subsequent attempts by first-time attempters.

3. Intensive follow-up treatment following an attempt is most appropriate and effective for high-risk patients.

4. Short-term cognitive-behavioral therapy with problem solving as a core intervention is effective in reducing select suicide risk factors.

5. Longer term treatment that targets specific skill deficits is required for reducing suicide attempts.

6. High-risk suicidal patients can be safely and effectively treated on an outpatient basis if acute hospitalization is available and accessible.
Clear guidance for mental health professionals is essential to ensure that patients receive the appropriate assessment and treatment services and that providers, as well as health care systems, are not put at increased risk for litigation.

\section{The Air Force Managing Suicidal Behavior Project}

In 2002, the U.S. Air Force (AF) began an initiative, the Managing Suicidal Behavior (MSB) Project, to enhance the clinical treatment arm of a broad public health suicide-prevention effort. This effort, called the Air Force Suicide Prevention Program, was created in 1996, under the leadership of General Thomas S. Moorman Jr., to provide a community approach to suicide prevention. The program's 11 initiatives address leadership involvement, improved collaboration among base helping agencies, new preventive and support services, multiple community suicide-education forums, policy changes, and new data collection and analysis (see Knox, Litts, Talcott, Feig, \& Caine, 2003). Suicide rates in the AF community have significantly decreased since the implementation of these initiatives (Knox et al., 2003; Staal \& Hughes, 2002), and analysis has estimated a $33 \%$ risk reduction for completed suicide (Knox et al., 2003). Although suicide rates in the U.S. population have maintained a slight downward trend since 1990, the AF rate has shown marked declines since the onset of the Air Force Suicide Prevention Program. The suicide rate for the AF dropped from 14.3 per 100,000 averaged across the 5 years prior to the onset of the program (1992-1996) to 9.2 for the 7 years following the onset of the program (1997-2003). This is compared with a decline from 11.9 to 11.0 for the general population and a decline from 24.2 to 22.2 for U.S. men ages $20-49$ years, which is a demographic group similar to the $81 \%$ male AF population. Figure 1 shows the trend lines over this 10 -year period for the AF, the general U.S. population, and U.S. men ages 20-49. The AF suicide rate fluctuates by year, and no claim for causation can be made; however, the decline in the suicide rate leaves room for optimism that continued efforts to prevent suicide may indeed save lives.

The Air Force Medical System (AFMS) is a large health care system with 74 military treatment facilities providing medical care to 2.4 million beneficiaries, including active duty members, retirees, and their families. Virtually all mental health services are provided through (a) Life Skills Support Centers (outpatient mental health services), (b) Alcohol and Drug Abuse Prevention and Treatment Programs, and (c) Family Advocacy Programs for prevention and treatment of family violence. Only a few AF facilities provide inpatient psychiatric care; most patients needing hospitalization are referred to civilian facilities or transported through the medical evacuation system to other military hospitals.

When managing suicidal behavior, AF mental health professionals have two primary responsibilities. First, they assist those who are in distress and who are at increased risk for suicide by conducting timely and comprehensive assessments of risk and providing or facilitating appropriate care. Second, they support leaders of military units in managing personnel at increased risk for suicide, as well as the impact these situations can have on the organization and mission. Similar to other behavioral health providers, AF providers are expected to evaluate the literature, assessment tools, and strategies for themselves. Most learning related to consultation with commanders about suicidality occurs on the job. In the event of a patient's suicide, the decisions and actions of providers and 


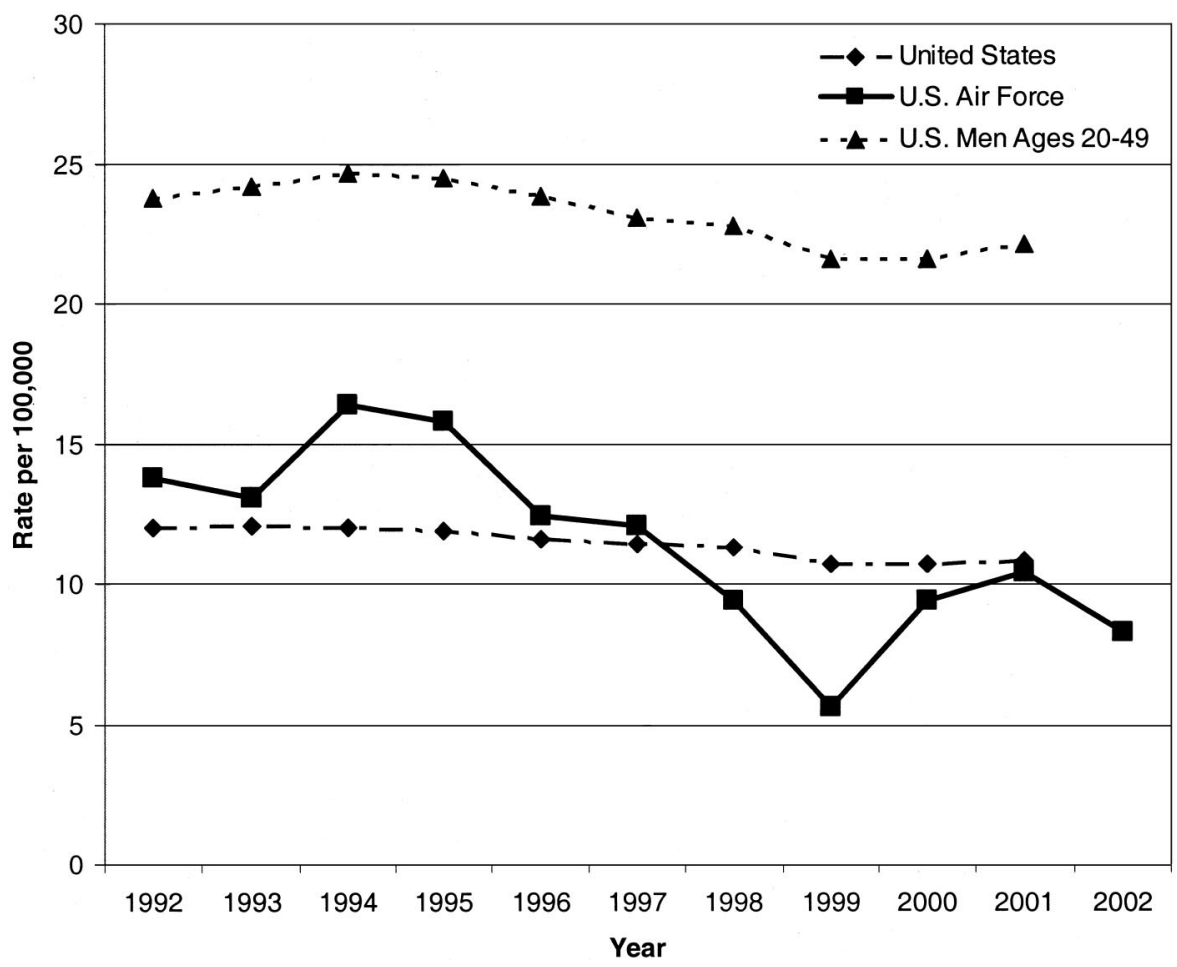

Figure 1. Air Force and general U.S. population suicide rates. (Data are from Arias, Anderson, Kung, Murphy, \& Kochanek, 2003; Knox et al., 2003.)

staff are evaluated by an assigned team that determines whether the standard of care has been met. However, there has been little AF consolidated guidance or training to help behavioral health professionals understand and meet this standard (as is true for most behavioral health systems).

The overarching goal of the MSB Project was to enhance quality of mental health care to suicidal patients through increased standardization and implementation of currently accepted practices in the field. The primary objectives were as follows: (a) to develop and disseminate a high-quality guide to AF mental health professionals on managing suicidal behavior; (b) to increase provider confidence in assessing and managing suicidal behavior; (c) to promote care consistent with current suicide assessment and management practices and empirical findings related to suicidality; and (d) to encourage individual mental health clinics to establish standardized suicide-management procedures (by means of local written policy) that are consistent with the MSB guide's recommendations. In developing the guide, a process was established for obtaining input and feedback from both potential users (behavioral health professionals) and other stakeholders (representative leaders of AF units, AFMS behavioral health leadership). Involving these parties throughout the development of the guide was expected to increase its relevance, acceptance, and ultimately its use in clinical practice and clinic policy.

This article presents the methodology used to develop a guide for assessing and managing suicidal behavior in the AF, a description of the content and format of the guide, a discussion of barriers and areas of concern that were encountered, and planned evaluation of the impact of the guide on the care provided by the AFMS behavioral health community.
Development of the Guide

\section{Sources of Information}

The primary focus of the development of the MSB guide was to create a document that addressed outpatient assessment and management of suicidal behaviors for specialty behavioral health clinics. As such, content related to inpatient treatment, communitybased suicide prevention, and primary care were considered to be outside the scope of the guide, except to the degree that outpatient behavioral health providers interacted with these other settings. To make the guide relevant and useful, we used several sources of information to identify recommendations and clinical strategies that would constitute high-quality care. These sources are discussed below.

Controlled research studies. Although much has been written on suicide, controlled studies on the clinical management of suicidal behavior are limited. Recent reviews of this literature (Hawton et al., 1998; Heard, 2000; Rudd, Joiner, \& Rajab, 2001) found no more than 25 randomized or controlled studies on the treatment of suicidality. A search of the PsycINFO and Medline databases, using the terms suicide, suicide prevention, suicide management, and suicide assessment to capture any additional controlled studies through July 2002, revealed only 2 additional journal articles meeting the criterion of being a randomized or controlled study (Khan, Warner, \& Brown, 2000; Motto \& Bostrum, 2001).

Existing professional guidelines. A number of articles, books, and other publications offering guidelines for managing suicidal behavior were identified and reviewed as resources for the MSB guide. These include Bongar (2002); Bongar, Maris, Berman, and Litman (1992); Jobes and Berman (1993); Joiner, Walker, Rudd, 
and Jobes (1999); Risk Management Foundation, Harvard Medical Institutions (1996); Rudd et al. (1999); and Rudd et al. (2001).

Assessment instruments. Brown (2001) recently reviewed assessment measures for adult suicidality from the National Institutes of Behavioral Health. This comprehensive review was used as a source to compare the broad range of instruments available.

Expert opinion. Two experts on suicidology were identified from the professional literature. Both civilian experts (David A. Jobes and M. David Rudd) were board certified in their professional fields, had published over 50 works on suicide, served as presidents of the American Association of Suicidology, and had prior experience with the U.S. military. Experts on policies and procedures within the AF behavioral health system were also identified. Both the civilian and military experts provided input through a series of working group meetings, consultations, and iterative reviews of draft documents.

Recognized organizational standards. Department of Defense instructions and directives provide policy for the military services, and AF instructions and pamphlets are policy documents specific to the AF. Six separate AF instructions or pamphlets and three Department of Defense instructions or directives provide policy related to managing suicidal behavior. To meet military-specific requirements, these policies were integrated throughout the guide.

Lessons learned from past suicides. Much has also been written about aspects of malpractice and actions or inactions that may constitute failure on the part of the clinician. Because standard-ofcare is often examined and ultimately determined within the context of malpractice litigation, we examined this literature for the key findings from this arena (Bongar, 2002; Jobes \& Berman, 1993). We also obtained a 15 -month review of suicide-related observations from inspections of AF clinics. The review related to adherence to local and AF health services policy.

In addition, observations from the AF's postsuicide Medical Incident Investigation (MII) reports from 2001 and 2002 were obtained to ensure that the guide addressed lessons learned from these incidents. An MII is conducted whenever an individual under the care of an AF medical treatment facility commits suicide. A team of relevant professionals from outside the involved facility evaluates the care provided and recommendations are made to the facility. In accordance with federal law (Confidentiality of Medical Quality Assurance Records, 2003), information from an MII report can be released only to certain authorized persons, including Department of Defense employees who need it to perform their duties. The in-depth analysis of an MII team provides important guidance for improving care.

Commander and first sergeant feedback. As noted earlier, AF mental health providers have two primary roles: They provide professional services both to their individual patients and to $\mathrm{AF}$ unit leadership. This is a delicate issue that requires providers to have a clear understanding of their responsibilities to each party and requires them to clearly communicate these responsibilities to meet ethical and professional military standards. It was important, therefore, that the MSB guide address clinical practice standards, consultation skills, and the interface of these two roles.

Effective guidance for consulting required an understanding of what types of support unit leaders need when they encounter members of their units at increased risk for suicide. Feedback was sought from a convenience sample of commanders and first sergeants (a senior enlisted leader in the unit) from different bases, both in the United States and in overseas locations. Respondents were provided with standardized questions and given the option of responding in writing or by telephone. Feedback from commanders and first sergeants on the responsiveness and assistance of mental health professionals in managing suicidal behavior was overwhelmingly positive, although discussion of isolated problem cases generally centered on communication issues between medical personnel and unit leaders.

\section{Development Process}

On the basis of information from these sources, a set of prototypic recommendations was drafted, and a working group comprising military and civilian mental health professionals was convened to review them and provide input. The working group met twice to discuss the content and format of the guide with emphasis on its relevance and acceptability to providers and staff in the field. The working group members also discussed logistical, ethical, and local concerns the guide might generate, as well as the readability and clarity of the guide. Finally, the group brainstormed ideas for additional content. The draft guide was substantially revised on the basis of feedback provided at the working group meeting and was reviewed by additional mental health clinicians who had not originally been involved in the development of the guide. Finally, a medical-legal consultant reviewed and endorsed the guide.

\section{The Air Force Guide for Managing Suicidal Behavior}

\section{Preface}

The preface defined the guide as a clinical resource that consolidates and synthesizes current knowledge and best practices related to management of suicidality. The recommendations were developed to reflect the standard of care within the U.S. health care system and were based on clinical research, the findings of civilian litigation cases, and AF policy. As such, the preface explicitly stated that this was not a mandate and was not defining a new standard of care.

\section{Summary of Empirical Findings on Clinical Management of Suicide}

Following the preface, a summary of empirical findings on clinical management of suicidality was presented. Five conclusions, each of which was incorporated into the recommendations, were highlighted. These were as follows:

1. Multiple attempters appear to be a unique group as compared with ideators and single attempters. They present a more severe clinical picture and accordingly are at higher suicide risk (Rudd et al., 1996). It is important to carefully assess multiple attempt status, incorporate it into plans for treatment intensity and duration, and consider it in military retention decisions.

2. Treatment of major psychiatric disorders does not appear to necessarily reduce suicidal behavior or the number of suicide attempts (Brent et al., 1997; Khan et al., 2000). Therefore, it is best to target suicidal behavior directly for treatment (Jobes \& Drozd, 2004; Jobes, Luoma, Jacoby, \& Mann, 2000). 
3. Short-term cognitive-behavioral and problem-solving approaches as core interventions are effective at reducing suicidal ideation, depression, and hopelessness for up to a year (see review in Rudd et al., 2001). Several studies of short-term treatment were done with the highest risk patients (i.e., multiple attempters). Therefore, it appears that even some high-risk suicidal patients may be safely and effectively treated on an outpatient basis (Linehan, Armstrong, Suarez, Allmon, \& Heard, 1991; Rudd et al., 1996). Indeed, considering patient preference and stigma issues, there is an increasing movement in the field to emphasize outpatient care as preferable to inpatient care (Jobes, 2000).

4. The strongest predictor of completed suicide during the 5 years following discharge from inpatient treatment is a reduction in the intensity of care, especially for those who have chronically elevated risk (Appleby et al., 1999). Furthermore, high-risk patients are disproportionately represented in treatment dropouts (Rudd, Joiner, \& Rajab, 1995). There is evidence that simply maintaining contact with treatment-refusing patients through a follow-up letter or phone call leads to reduced suicide rates over a 5-year period, as compared with no contact (Motto \& Bostrum, 2001). Chronic-risk individuals (multiple attempters) are likely to benefit from ongoing monitoring or treatment and, thus, clinic processes to ensure contact and follow-up may be helpful.

5. In civilian community studies, a majority (64\%) of individuals who committed suicide saw their general medical provider in the month before their death (Andersen, Andersen, Rosholm, \& Gram, 2000; Appleby et al., 1999; Luoma, Martin, \& Pearson, 2002). A review of AF medical utilization records showed similar trends. In 2001, 33\% of those who completed suicide visited a military treatment facility in the month prior to their death, and 56\% saw a physician within 3 months of their death. Therefore, it is important to include primary care providers in suicide-management efforts.

\section{Errors in the Management of Suicidality}

To help the staff at mental health clinics avoid repeating errors that have resulted in poor outcomes, the guide presented a review of common errors in the management of suicidality. Findings related to suicide from the AF Investigation Agency's Health Services Inspections were presented to encourage careful attention to areas in which problems have been noted. Bongar et al.'s (1992) failure scenarios were also presented to increase awareness of potentially negligent practices. Finally, the guide presents a series of practices that can provide protection in litigation, derived by Jobes and Berman (1993) from civilian malpractice suits.

\section{Suicide-Management Topic Areas and Recommendations}

The guide presented the 18 recommendations for managing suicidal behavior, organized into 8 topics. The scope of the recommendations was the management of suicidal behavior and did not address treatment approaches per se. The topic areas and recommendations are presented in Table 1.
In some cases, recommendations were for a specific practice (e.g., "Formally assess suicide risk at every initial evaluation, and as clinically indicated at follow-up contacts"). In other cases, recommendations were to establish a local policy for a given clinical issue (e.g., "Establish a written plan for after-hours evaluations"). After each recommendation, detailed guidance was provided for meeting the recommendation. These how-to sections included best practices that may, in some cases, exceed the minimum standard of care. In many cases, no single approach or practice was endorsed; instead, relevant issues to consider, various options, and recommendations were presented. Final decisions about how to meet the recommendations were left to the local clinic leadership and, ultimately, to individual providers.

\section{Tools, Templates, and Resources}

In addition to providing recommendations, a set of practical tools and resources related to risk assessment and management were included in an extensive set of appendixes. The goal of the tools was to make it easy for clinic providers and staff to adhere to the recommendations. The specific contents were as follows:

Process-of-care flowchart. Figure 2 shows the flowchart that was provided to graphically display the process of care for management of suicidal behavior in mental health clinics. It includes steps for risk screening, risk assessment, decision points depending on level of risk, risk-management strategies, reassessment and monitoring, and termination of care when appropriate. In the actual guide, each step on the flowchart was referenced to the recommendation in the guide to which it related.

Clinic operating instruction template. This template was constructed around the 18 recommendations and provided a model for documenting local policies and procedures. It was expected that clinic leaders would adapt the template to the needs of their local facilities or incorporate aspects of it into their existing operating instructions. It addressed each of the 18 recommendations.

Suicide assessment instruments table. This table was adapted from Brown (2001) and contained a comprehensive listing of suicide assessment measures for adults. For each measure, the listing included information on the mode of administration, number of factors measured, number of items, whether data on predictive validity exist, and the settings in which studies evaluated it. This manuscript is available at www.nimh.nih.gov/research/ adultsuicide.pdf.

Selected suicide-assessment instruments. Copies of the Suicide Status Form and the Suicide Tracking Form (Jobes et al., 2000) were modified and provided for clinic personnel to duplicate and use. These instruments were selected from among multiple high-quality instruments because of their good psychometic properties evidenced specifically with AF clinical samples (Jobes, Wong, Drozd, \& Kiernan, 2002).

Sample crisis response plan cards. The use of crisis response plan cards as part of the treatment plan (Rudd et al., 2001) was discussed in the guide, and these sample cards were provided to demonstrate them (see Appendix A). A crisis response plan is an individually negotiated behavioral plan for what the patient will do to cope instead of using suicidal behavior. The crisis response plan is written concretely, to include a definition of when it is to be used (e.g., when suicidal thoughts occur) and specific, concrete steps the patient should use to ensure safety and deactivate the suicidal mode. The plan can be written on a card that the patient can carry 
Table 1

Topic Areas and Recommendations

\begin{tabular}{|c|c|}
\hline Topic area & Recommendation \\
\hline $\begin{array}{l}\text { Assessment of suicide } \\
\text { risk }\end{array}$ & $\begin{array}{l}\text { Formally assess suicide at every initial evaluation and as clinically indicated } \\
\text { at follow-up contacts. } \\
\text { Use appropriate measures to assess suicidality. }\end{array}$ \\
\hline $\begin{array}{l}\text { A decision-making } \\
\text { framework }\end{array}$ & $\begin{array}{l}\text { Determine suicide risk level on the basis of assessment information and } \\
\text { match to appropriate suicide-specific interventions. }\end{array}$ \\
\hline $\begin{array}{l}\text { Outpatient management } \\
\text { strategies }\end{array}$ & $\begin{array}{l}\text { Specifically target suicidal symptoms and risk factors in the formal } \\
\text { outpatient treatment plan. } \\
\text { Take steps to safeguard the environment; limit accessibility to means of } \\
\text { self-harm. } \\
\text { Establish processes for ongoing monitoring of suicide risk } \\
\text { Use management strategies that are uniquely applicable to active duty } \\
\text { members }\end{array}$ \\
\hline $\begin{array}{l}\text { Documentation } \\
\text { strategies }\end{array}$ & $\begin{array}{l}\text { When documenting a suicide-risk assessment, include both current and } \\
\text { historical risk factors, observations from the session, rationale for actions } \\
\text { taken or considered but not taken, and follow-up plans, including a } \\
\text { response plan when there is evidence of increased suicidality }\end{array}$ \\
\hline $\begin{array}{l}\text { Coordinating with } \\
\text { inpatient care }\end{array}$ & $\begin{array}{l}\text { Establish a process for coordination when patients are hospitalized } \\
\text { Reassess a patient's needs (including suicidality) following inpatient or } \\
\text { partial hospitalization before assuming or reassuming responsibility for } \\
\text { outpatient care }\end{array}$ \\
\hline $\begin{array}{l}\text { Clinic support and peer } \\
\text { consultation }\end{array}$ & $\begin{array}{l}\text { Use a high-interest log as a clinic tracking procedure for suicidality, and } \\
\text { share information between relevant specialty mental health clinics } \\
\text { Consult professional peers regularly regarding suicidal patients and } \\
\text { document the consultation. }\end{array}$ \\
\hline $\begin{array}{l}\text { Ensuring continuity of } \\
\text { care }\end{array}$ & $\begin{array}{l}\text { Use a standardized follow-up and referral procedure for all previously } \\
\text { suicidal patients dropping out of treatment prematurely } \\
\text { Ensure clinical coverage when the primary provider is unavailable } \\
\text { Establish a procedure for ensuring continuity of care during } \\
\text { provider and patient transitions }\end{array}$ \\
\hline $\begin{array}{l}\text { Links with the } \\
\text { community }\end{array}$ & $\begin{array}{l}\text { Establish a written plan for after-hours evaluations. Ensure other relevant } \\
\text { agencies and individuals (i.e., security forces, first sergeants, etc.) are } \\
\text { aware of the plan } \\
\text { Mental health providers and staff are the primary resource within the base } \\
\text { community regarding mental health issues; as such, they should serve as } \\
\text { consultants to unit leadership regarding the management of at-risk } \\
\text { personnel } \\
\text { Use community support resources in managing suicidal behavior }\end{array}$ \\
\hline
\end{tabular}

in a wallet or purse. The behavior-oriented crisis response plan addresses many of the drawbacks of the commonly used nosuicide contract discussed by Bongar (2002), such as the false security a therapist may derive from a no-suicide contract based only on an agreement with an unstable patient.

Sample risk-assessment documentation. Examples of a comprehensive risk-assessment section of a clinical note were provided for both an initial evaluation and a follow-up session.

Sample suicide-risk-assessment overprint. An overprint of a medical record form was provided that contained all recommended domains for assessing suicide risk (see Appendix B). This form was provided to facilitate comprehensiveness in assessment and to provide an efficient way of thoroughly documenting findings, status, and recommendations.

Sample memorandum of understanding with inpatient care facilities. Most military treatment facilities do not have inpatient psychiatric services and, therefore, rely on civilian facilities to provide inpatient care when necessary. Communication and collaboration between the military treatment facility and the civilian facility is essential to ensure appropriate follow-up after discharge. A memorandum of understanding with frequently used inpatient care facilities can facilitate smooth discharge coordination. There- fore, a sample and template memorandum of understanding was provided.

Template patient-information sheet. As part of the informed consent process, clients in AF mental health clinics are provided with an information sheet outlining various clinic procedures and the limits of privacy for information they share with a provider. This template patient-information sheet contained information about policies and procedures for managing suicidal behavior recommended for sharing with patients at the initial contact.

Template no-show letter. The template letter encouraged patients who missed a scheduled appointment to contact the clinic to reschedule.

Access-to-care handout. This trifold brochure detailed the procedures for scheduling routine appointments and for accessing after-hours care in emergencies.

\section{Barriers and Areas of Concern}

Stakeholders expressed several areas of concern during the development of the MSB guide. These concerns involved potential barriers to use of the guide, and attempts were made to address these concerns as the guide was developed. 


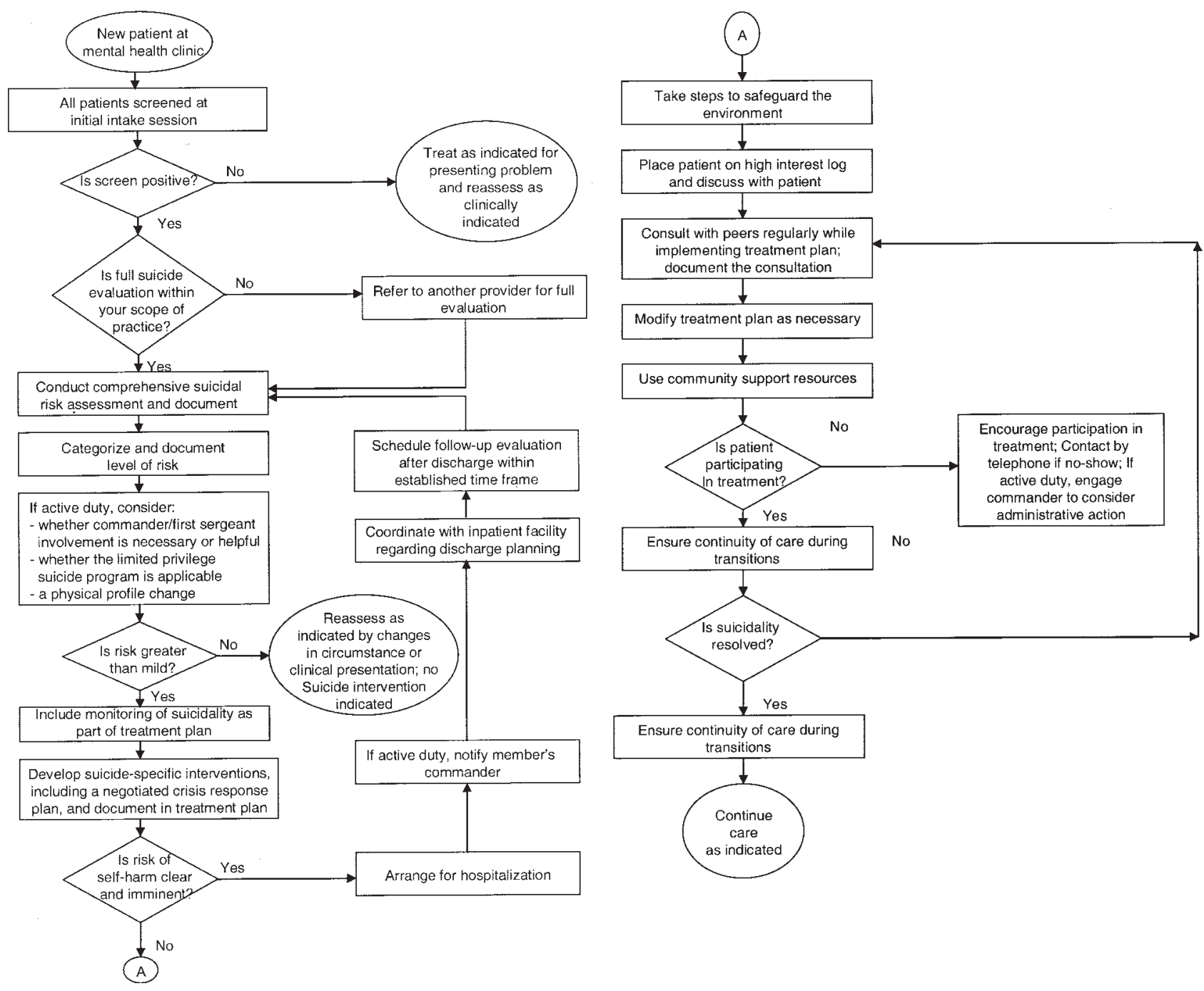

Figure 2. Process-of-care flowchart.

One concern was that the guide would be seen as a new and higher standard of care for the management of suicidal patients. Given the fact that some of the material in the guide represented best practices that do exceed current practice patterns that are commonly accepted as standard of care, there was potential for readers to conclude that the bar had been raised.

This concern may reflect a misunderstanding of what defines the standard of care as it relates to suicidality. As discussed by Jobes and Berman (1993), the standard of care is defined as what a typical, similarly trained provider in a community would do in a given circumstance. In a legal sense, the standard cannot be established in advance because it is defined in relation to a specific situation. For example, clinical performance is evaluated in terms of the standard of care in litigation proceedings and postsuicide investigations. In these situations, a jury, sentinel event investigation team, or MII board ultimately determines this standard related to a specific case. The MSB guide was developed to reflect those practices that have been judged to be the standard of care in various cases, but it does not-and, by definition, cannot-define it. Furthermore, it is important to note that the guide is not a policy document for the AFMS; it is instead a compilation of resources, tools, and recommendations into one document. Just as reading a book or journal article or attending a workshop does not change the standard of care to which a provider must adhere, reading the MSB guide does not raise the bar for AF providers (although any of these may increase awareness of a standard that already exists).

To address this concern, the preface section of the guide was included to outline the intended scope and purpose of the document. Definitive statements were made that the guide should not be used as a static or definitive statement of the standard of care in MIIs or legal investigations and proceedings. The preface also strongly encouraged clinicians and clinic leaders to incorporate relevant information from the guide into their practices and clinic policy documents because these are one of the appropriate benchmarks on which clinical performance can be judged when standard-of-care determinations are made. Finally, the guide is considered a fluid document that will be updated to reflect ongoing scientific and clinical advances.

A second concern was whether a guide on the management of suicidal behaviors could actually impact the practice patterns of 
mental health professionals in the AFMS. Ample evidence exists that clinical practice guides alone do not change the behaviors of practitioners (Freemantle et al., 2002). Shekelle, Woolf, Eccles, and Grimshaw (1999) concluded that multifaceted interventions are needed to disseminate and implement guidelines, including workshops, feedback to providers on suboptimal practice, social influence approaches (i.e., local consensus building, marketing, use of opinion leaders), and provider reminders.

This issue was addressed in a three-tiered approach aimed at providing a wide dissemination and penetration across the AFMS mental health community. First, the guide was paired with provider training. Representatives from each military treatment facility were offered the opportunity to attend a 12-hr training seminar designed to reflect the content of the guide and to include role-play and practical examples of common clinical scenarios. Because funding levels would not accommodate training for all AF mental health providers and staff, a train-the-trainer model was adopted so individuals who were trained could return to their clinics and train others. Videos were developed to serve as tools for trained individuals to use with others in their clinics. The videos include material on assessment, outpatient-management strategies, and consulting with commanders. As with the on-site training, the videos contained material from the guide, as well as role-play demonstrations of patient-provider interactions and providercommander interactions. Second, the extensive set of tools and templates, described earlier, was provided to facilitate easy adherence to the recommendations in the guide. Finally, the guide was released through an extensive marketing campaign to influence opinion at all levels within the AFMS. Marketing efforts were directed toward providers, clinic and military treatment facility leaders, and other AFMS leaders. Senior nonmedical AF leaders were also informed of the project to ensure their awareness and support.

\section{Evaluation Plan}

The success of the MSB project will be measured by assessing changes in clinician confidence and beliefs related to suicide care, clinical behaviors of providers, and clinic policies across the AFMS. The details of the evaluation are outside the scope of this manuscript. However, the evaluation plan for the guide and for training will address the following areas:

1. Dissemination (i.e., did the intended target groups receive the MSB guide and training?);

2. Changes in individual confidence, beliefs, and professional practices about suicide care following the training (i.e., immediately after training and 6 months after training);

3. Changes in clinic policy and procedures are consistent with MSB recommendations (6 months following the training).

\section{Implications for Providers}

Suicidality frequently presents a challenge to providers. The MSB project was designed to help mental health professionals provide evidence-supported clinical care and to feel more confi- dent in managing suicidal patients. Specifically, we hope providers will apply the five conclusions from the literature outlined previously:

1. Multiple suicide attempters represent a unique at-risk group and should be managed accordingly. This certainly includes assessing suicide attempt history but also suggests that patients in this group should be considered to be at chronic risk and treated with a higher level of care than non-multiple-attempt patients who present with similar acute symptoms.

2. Suicidal behavior should be targeted directly in the treatment plan. Simply treating an underlying condition, such as depression, on the assumption that suicidal risk will abate as the condition improves is insufficient.

3. Short-term cognitive-behavioral therapy can be effectively used with suicidal patients (including some highrisk patients). Use of management strategies based on a cognitive framework, such as establishing a crisis response plan, can help reduce risk and avoid hospitalization.

4. Ongoing monitoring is essential for chronic-risk individuals. Use of telephone contacts between office visits and even letters or emails for high-risk patients who refuse to come to the clinic can help provide needed support.

5. Other medical providers, especially primary care providers, may have an opportunity to impact suicidal patients and should be involved in suicide-management efforts. Within appropriate boundaries for confidentiality and informed consent, we strongly recommend that medical and mental health providers communicate high-risk status for patients to whom both providers are providing care.

In addition to its potential to impact individual provider practices, the guide provides recommendations for establishing local policy and procedures. Written policy and procedures can help standardize high-quality care within a health care agency. Policy and procedure documents also provide providers with legal protection for their actions, since the written policy establishes a usual and customary practice for managing specific clinical situations. To the degree that providers within the agency are complying with local policy, they are meeting the standard of care.

Although the military environment is unique from that of other communities in many ways, the methodology and much of the content used in the AF's MSB guide is applicable to other settings. University health care settings, school districts, law enforcement agencies, correctional systems, and other occupation-based communities may benefit from similar initiatives to meet the unique needs of their beneficiaries and, where relevant, their occupational requirements. Outcome evaluation of the training based on the guide will provide evidence as to whether provider behaviors and clinic policy can, in fact, be positively impacted across a large number of clinics through a focused training intervention. The results of this evaluation will lend support for those in other health care organizations and agencies who are advocating for increased 
suicide-prevention resources in the clinical arena. Improving standardization and promoting strategies for quality care for suicidal patients can help enhance provider confidence in dealing with this difficult clinical issue, can enhance quality of care, and may ultimately save lives.

\section{References}

American Psychiatric Association. (2000). Diagnostic and statistical manual of mental disorders (4th ed., text rev.). Washington, DC: Author.

American Psychiatric Association. (2003). Practice guideline for the assessment and treatment of patients with suicidal behaviors. Retrieved December 17, 2003, from http://www.psych.org/psych_pract/treatg/pg/ pg_suicidalbehaviors.pdf

Andersen, U. A., Andersen, M., Rosholm, J. U., \& Gram, L. F. (2000). Contacts to the health care system prior to suicide: A comprehensive analysis using registers for general and psychiatric hospital admissions, contacts to general practitioners and practicing specialists and drug prescriptions. Acta Psychiatrica Scandinavica, 102, $126-134$

Appleby, L., Shaw, J., Amos, T., McDonnell, R., Harris, C., McCann, K., et al. (1999). Suicide within 12 months of contact with mental health services: National clinical survey. British Medical Journal, 318, 12351239.

Arias, E., Anderson, R. N., Kung, H. C., Murphy, S. L., \& Kochanek, K. D. (2003). Deaths: Final data for 2001. National Vital Statistics Reports, 52(3). (DHHS Publication No. PHS 2003-1120). Hyattsville, MD: National Center for Health Statistics.

Bongar, B. (2002). The suicidal patient: Clinical and legal standards of care (2nd ed.). Washington, DC: American Psychological Association.

Bongar, B., \& Harmatz, M. (1991). Clinical psychology graduate education in the study of suicide: Availability, resources, and importance. Suicide and Life-Threatening Behavior, 21, 231-244.

Bongar, B., Maris, R. W., Berman, A. L., \& Litman, R. E. (1992). Outpatient standards of care and the suicidal patient. Suicide and LifeThreatening Behavior, 22, 453-478.

Brent, D. A., Kolko, D., Birmaher, B., Baugher, M., Roth, C., Iyengar, S., et al. (1997). A clinical psychotherapy trial for adolescent depression comparing cognitive, family, and supportive therapy. Archives of General Psychiatry, 54, 877-885.

Brown, G. K. (2001). A review of suicide assessment measures for intervention research with adults and older adults. Retrieved February 6, 2002, from http://www.nimh.nih.gov/research/adultsuicide.pdf

Cantor, C. H. (2000). Suicide in the Western world. In K. Hawton \& K. van Heeringen (Eds.), The International Handbook of Suicide and Attempted Suicide (pp. 9-28). New York: Wiley.

Chemtob, C. M., Bauer, G., Kinney, B., \& Hamada, R. S. (1988). Patients' suicides: Frequency and impact on psychiatrists. American Journal of Psychiatry, 145, 224-228.

Chemtob, C. M., Bauer, G., Torigoe, R. Y., \& Hamada, R. S. (1988). Patient suicide: Frequency and impact on psychologists. Professional Psychology: Research and Practice, 19, 416-420.

Confidentiality of Medical Quality Assurance Records: Qualified Immunity for Participants, 10 U.S.C. $\$ 1102$ (2003).

Drozd, J. F., Lancaster, D. P., Zak, M. L., \& Peters, K. R. L. (2001). [Suicidality in a clinical sample]. Unpublished raw data.

Ellis, T. E., \& Dickey, T. O. (1998). Procedures surrounding the suicide of a trainee's patient: A national survey of psychology internships and psychiatry residency programs. Professional Psychology: Research and Practice, 29, 492-497.

Freemantle, N., Harvey, E. L., Wolf, F., Grimshaw. J. M., Grilli, R., \& Bero, L. A. (2002). Printed educational materials: Effects on professional practice and health care outcomes (Cochrane review). In The Cochrane Library (Issue 2). Oxford: Update Software.
Gutheil, T. G. (1992). Suicide and suit: Liability after self-destruction. In D. Jacobs (Ed.), Suicide and clinical practice (pp. 147-167). Washington, DC: American Psychiatric Press.

Hawton, K., Arensman, E., Townsend, E., Bremner, S., Feldman, E., Goldney, R., et al. (1998). Deliberate self-harm: A systematic review of the efficacy of psychosocial and pharmacological treatments in preventing repetition. British Medical Journal, 317, 441-447.

Heard, H. L. (2000). Psychotherapeutic approaches to suicidal ideation and behavior. In K. Hawton \& K. van Heeringen (Eds.), The international handbook of suicide and attempted suicide (pp. 503-518). New York: Wiley.

Jobes, D. A. (2000). Collaborating to prevent suicide: A clinical-research perspective. Suicide and Life-Threatening Behavior, 30, 8-17.

Jobes, D. A., \& Berman, A. L. (1993). Suicide and malpractice liability: Assessing and revising policies, procedures, and practice in outpatient settings. Professional Psychology: Research and Practice, 24, 91-99.

Jobes, D. A., \& Drozd, J. F. (2004). The CAMS approach to working with suicidal patients: Psychotherapy with suicidal patients. Journal of Contemporary Psychotherapy, 34, 73-85.

Jobes, D. A., Luoma, J. B., Jacoby, A. M., \& Mann, R. E. (2000). Manual for the collaborative assessment and management of suicidality (CAMS). Unpublished manuscript.

Jobes, D. A., Wong, S., Drozd, J., \& Kiernan, A. (2002, September). An effectiveness study of CAMS vs. treatment as usual with suicidal outpatients. Paper presented at the Ninth European Symposium of Suicide and Suicidal Behavior, Warwick, England.

Joiner, T. E., Walker, R. L., Rudd, M. D., \& Jobes, D. A. (1999). Scientizing and routinizing the assessment of suicidality in outpatient practice. Professional Psychology: Research and Practice, 30, $447-$ 453.

Khan, A., Warner, H. A., \& Brown, W. A. (2000). Symptom reduction and suicide risk in patients treated with placebo in antidepressant clinical trials: An analysis of the Food and Drug Administration database. Archives of General Psychiatry, 57, 311-317.

Knox, K. L., Litts, D. A., Talcott, G. W., Feig, J. C., \& Caine, E. D. (2003). Risk of suicide and related adverse outcomes after exposure to a suicide prevention programme in the US Air Force: Cohort study. British Medical Journal, 327, 1376-1380.

Linehan, M., Armstrong, H., Suarez, A., Allmon, D., \& Heard, H. (1991). Cognitive-behavioral treatment of chronically parasuicidal borderline patients. Archives of General Psychiatry, 48, 1060-1064.

Luoma, J. B., Martin, C. E., \& Pearson, J. L. (2002). Contact with mental health and primary care providers before suicide: A review of the evidence. American Journal of Psychiatry, 159, 909-916.

Meyer, R. G., Landis, E. R., \& Hayes, J. R. (1988). The law for psychotherapists. New York: Norton.

Motto, J. A., \& Bostrum, A. G. (2001). A randomized controlled trial of postcrisis suicide prevention. Psychiatric Services, 52, 828-833.

Pope, K., \& Tabachnick, B. (1993). Therapists' anger, fear, and sexual feelings: National survey of therapist responses, client characteristics, critical events, formal complaints, and training. Professional Psychology: Research and Practice, 24, 142-152.

Risk Management Foundation, Harvard Medical Institutions. (1996). Guideline for identification, assessment, and treatment planning for suicidality. Retrieved December 3, 2002, from http://www.rmf.harvard .edu/rmlibrary/clinical-guidelines/suicide/body.html

Rudd., M. D., Joiner, T. E., Jobes, D. A., \& King, C. A. (1999). The outpatient treatment of suicidality: An integration of science and recognition of its limitations. Professional Psychology: Research and Practice, 30, 437-446.

Rudd, M. D., Joiner, T. E., \& Rajab, M. H. (1995). Help negation after 
acute suicidal crisis. Journal of Consulting and Clinical Psychology, 63, 499-503.

Rudd, M. D., Joiner, T. E., \& Rajab, M. H. (2001). Treatment of suicidal behavior: An effective, time limited approach. New York: Guilford Press.

Rudd, M. D., Rajab, M. H., Orman, D., Stulman, D., Joiner, T., \& Dixon, W. (1996). Effectiveness of an outpatient problem-solving intervention targeting suicidal young adults: Preliminary results. Journal of Consulting and Clinical Psychology, 64, 179-190.

Shekelle, P. G., Woolf, S. H., Eccles, M., \& Grimshaw, J. (1999). Clinical guidelines: Developing guidelines. British Medical Journal, 318, 593-596.

Staal, M. A., \& Hughes, T. G. (2002). Suicide prediction in the U.S. Air Force: Implications for practice. Professional Psychology: Research and Practice, 33, 190-196.

Appendix A

\section{Sample Crisis Response Plan Card}

When thinking about suicide, I agree to do the following:

Step 1: Try to identify my thoughts and specifically what's upsetting me

Step 2: Write out and review more reasonable responses to my suicidal thoughts

Step 3: Do things that help me feel better for about 30 min (e.g., taking a bath, listening to music, going for a walk)
Step 4: Repeat all of the above

Step 5: If the thoughts continue, get specific, and I find myself preparing to do something, I call the clinic at:

Step 6: If I cannot reach anyone at the clinic, I call:

Step 7: If I'm still feeling suicidal and don't feel like I can control my behavior, I go to the emergency room

\section{Appendix B}

\section{Medical Record Overprint}

Suicide Risk Assessment Note

S. A comprehensive suicidality assessment was conducted due to: (check one)

Referral source identified suicidal symptoms or risk factors

_ Patient reported suicidal thoughts/feelings on intake paperwork/assessment tools

_ Patient reported suicidal thoughts/feelings during the intake interview

_ Recent event already occurred

Other:

Y N Suicide Ideation:

- Frequency: Never Rarely Sometimes Frequently Always

- Intensity: Brief and fleeting Focused deliberation Intense rumination

Other:

- Duration: __ Seconds __ Minutes ___ Hours

Y N Current Intent

- Subjective reports:

- Objective signs:

Y N Suicide Plan:

- When

- Where

- How Y N Access to means

Y N Suicide Preparation

Y N Suicide Rehearsal

Y N History of Suicidality

- Ideation

- Single Attempt

- Multiple Attempts

Y N Impulsivity

- Subjective reports:

- Objective signs:

Y N Substance abuse

Describe:

Y N Significant loss

Describe: 


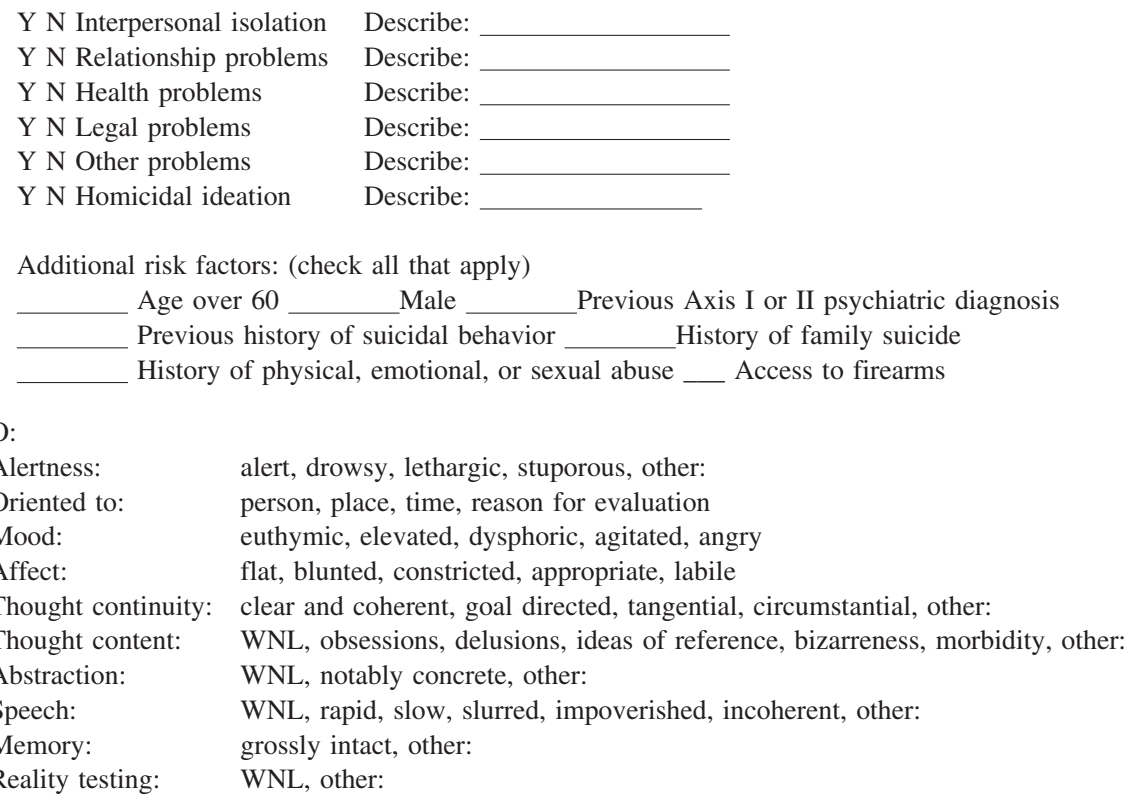

Notable behavioral observations:

\section{A: Current level of suicide risk: No Significant Risk Mild Moderate Severe Extreme}

DSM-IV-TR Diagnosis:

Axis I:

Axis II:

Axis III:

Axis IV:

Axis V:

P: At the current time, outpatient care can/cannot provide sufficient safety and stability. Intervention plan for safety is:

1.

2.

3.

4.

Patient agrees to this plan: $\mathrm{Y} \mathrm{N}$

Patient was provided a written crisis response plan: $\mathrm{Y} N$

Patient will be entered on the high-interest log: Y N

Hospitalization is/is not necessary. Rationale:

Special precautions necessary:

Persons notified of increased risk: spouse/commander/First Sergeant/PCM/friend/none/other:

Additional Information:

Note. $\mathrm{S}=$ subjective; $\mathrm{O}=$ objective; $\mathrm{WNL}=$ within normal limits; $\mathrm{A}=$ assessment; DSM-IV-TR = Diagnostic and Statistical Manual of Mental Disorders (4th ed., text revision; American Psychiatric Association, 2000); $\mathrm{P}=$ plan; $\mathrm{PCM}=$ primary care manager.

Received December 23, 2003

Revision received May 17, 2004

Accepted October 27, 2004 